Criação/Música 


\section{Vila Socó meu amor}

\section{GIIBERTO MENDES}

C C Tão devemos esquecer os nossos irmãos da Vila Socó, transformados em cinzas, lixo em pó. A tragédia da Vila Socó mostra como o trabalhador é explorado, esmagado sem nenhum dó."

Espanta-me a atualidade dessa constataçáo que fiz, já quase sete anos passados, ao escrever o texto para minha pequena peça coral Vila Socó meu amor. Nada mudou. Na verdade, até que mudou, para pior!

Nunca o trabalhador foi tão explorado, tão enganado, sob o tacáo do medieval Senhor dos impostos, agora talvez com o consolo de não estar só, ter por companheiros de infortúnio a classe média, os aposentados em geral. A classe dirigente, numa boa, não abre mão de nada, o povo que faça os sacrifícios impostos pelos planos econômicos "salvadores".

Com minha música, pretendi ter feito alguma coisa in memoriam dos mortos por aquela verdadeira bomba de Hiroshima que foi a explosão da Vila Socó. Por isso a lembrança, no título, de Alain Resnais, da imensa piedade pelo destino dos homens, que seu extraordinário filme comunica.

Meu colega Celso Delneri dirigia um coral feminino no Departamento de Música da Escola de Comunicaçóes e Artes da USP e me havia pedido uma música. O horror diante da terrível notícia deu-me o impulso. Quase um improviso, ao correr dos dedos no piano, a música foi pensada para vozes femininas, à maneira das canções corais dos partisans da regiáo do Voronejo, no tempo da grande guerra pátria dos russos contra o nazismo. Um mesmo período musical é repetido cinco vezes, com dois textos que também sáo repetidos alternadamente, de acordo com aquele minimalismo natural que encontramos na música folclórica de muitos povos.

Quando cantada nas imediaçóes de Cubatáo, a música comove a audiência, que já chegou a chorar. Năo vou me orgulhar por provocar tristeza nos outros, mas me satisfez saber que denunciar funciona. Mas até que ponto?

A despeito das promessas e alegadas realizaçóes, o meio ambiente continua sombriamente poluído. Volta e meia Cubatáo entra em estado de alerta; ainda há pouco tempo explodiu e ardeu durante seis horas um grande tambor de gás, colocando em perigo toda a Baixada Santista, que esteve à beira de outra tragédia, de muito maiores proporçóes do que a de Vila Socó. $O$ descaso não tem fim. 


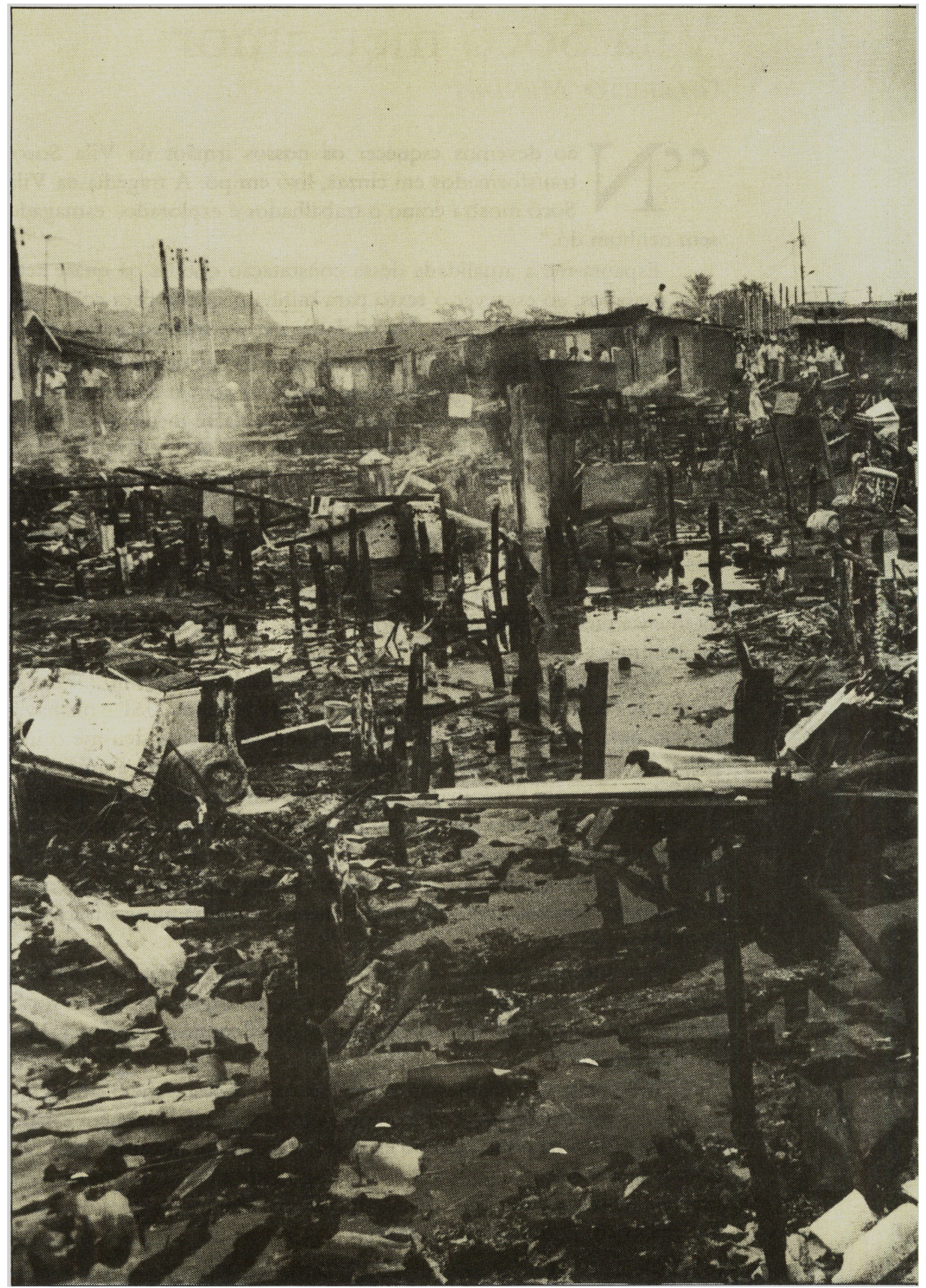




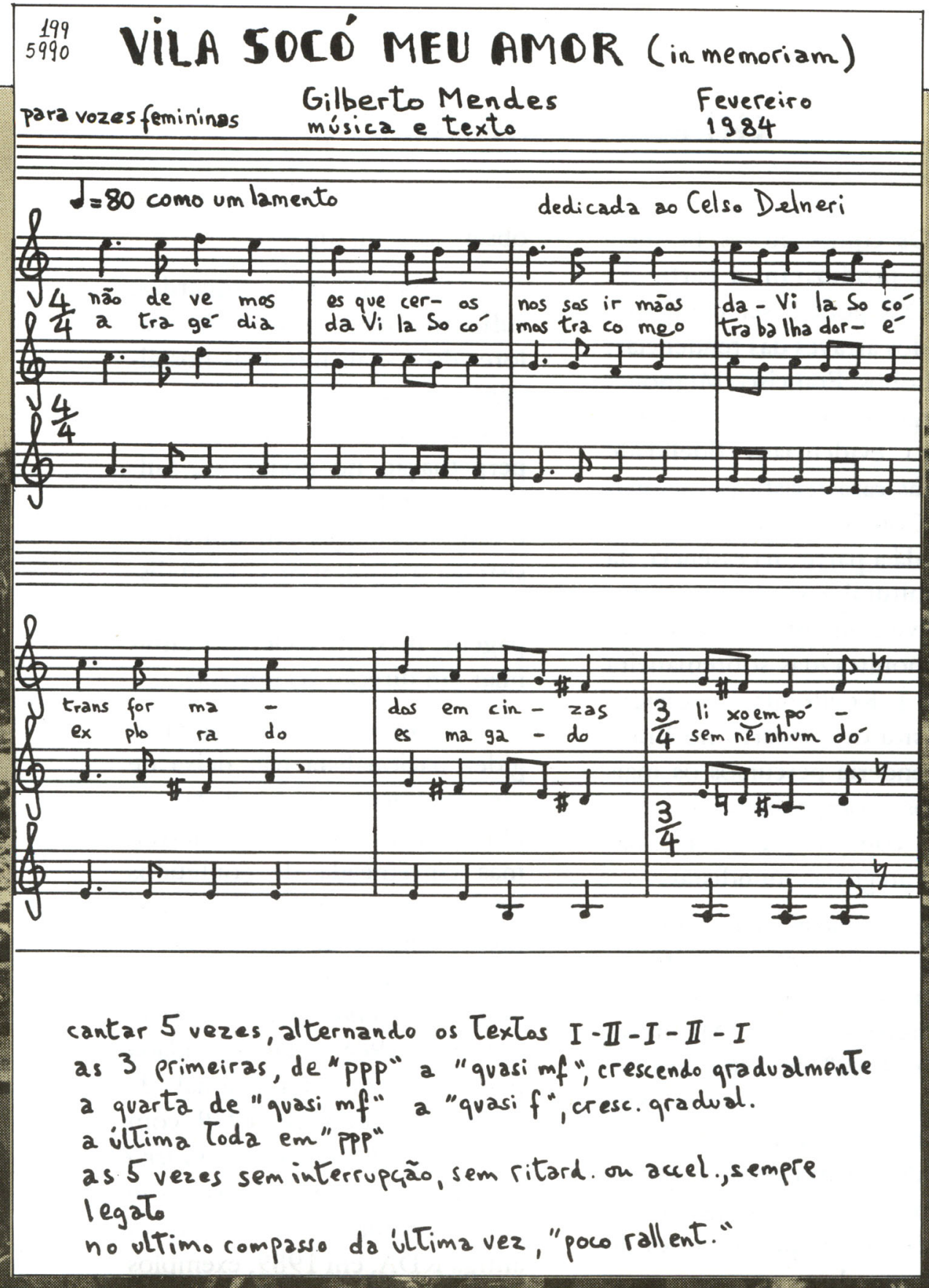

cantar 5 vezes, alternando os Textos I-II-I - II - I

as 3 primeiras, de "PPP" a "quasi mf", crescendo gradualmente a quarta de "quasi mf" a "quasi f", cresc. gradual. a iltima Toda em" ppp"

as 5 vezes sem interrupcão, sem ritard. on accel., sempre legato

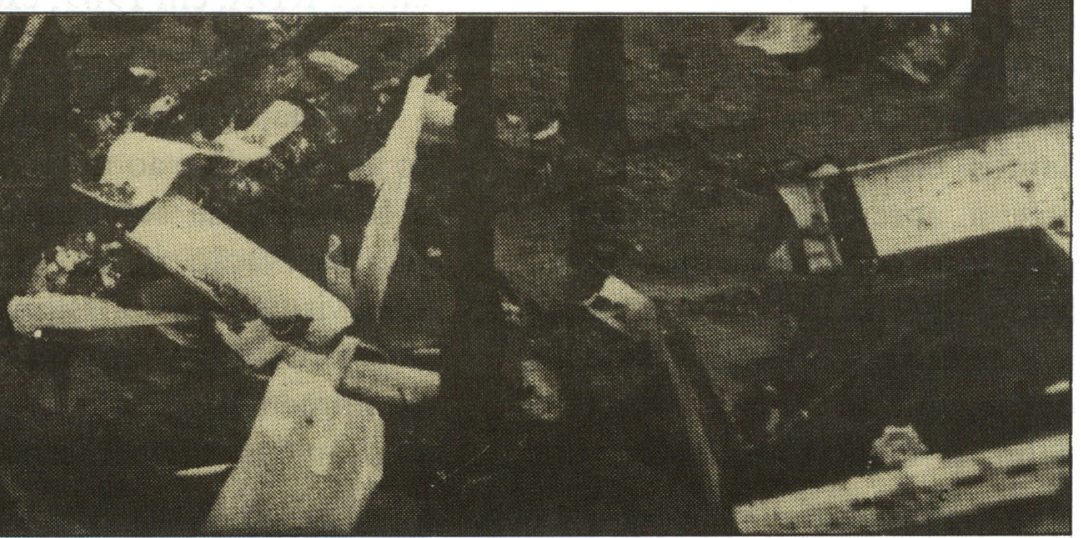




\section{GILBERTO MENDES}

Os compositores brasileiros que produziram a partir do século $\mathrm{XX}$ podem ser compartimentados através das tendências. Villa-Lobos, Francisco Mignone, Camargo Guarnieri e Cláudio Santoro evidenciam fidelidade básica às características nacionalistas. Com a ruptura de mercado que se dá a partir, na essência, da ação cultural voltada às correntes universalmente contemporâneas, monitoradas sobremaneira por H. J. Koellreutter, a criação da música de concerto no Brasil empreenderia percursos os mais diversos, comprometendo-se, e muito, com.o que ocorre nas várias categorias mundistas.

É possível ser Gilberto Mendes, hoje, o mais significativo compositor-pensador deste país. Signatário do "Manifesto Música Nova" de 1963, em nenhum momento deixou de produzir, escrever textos e o seu trabalho demonstra desde a gênese da composiçáo homogeneidade e coerência, sempre na busca do novo, entenda-se este, sem pressionamento. $\mathrm{O}$ Festival Música Nova, criado por ele, nasce em Santos em 1962; perdura até hoje a apresentar fundamental produção contemporânea brasileira e internacional e, em sendo por acréscimo o amplo leque de opçóes que se abrem, sobremaneira, a Gilberto Mendes, um observador infatigável.

Homem das esquerdas, suficientemente cônscio dos valores do socialismo, mas nostálgico crítico dos erros humanos - entre os quais a distorção da perpetuaçáo no poder - , Gilberto Mendes persiste socialista e tem esperanças em um novo sistema a contrapor o capitalismo em suas multifacetadas roupagens, mas em acelerado caminhar em direçáo ao impasse.

$O$ arguto observador da rigidez nacionalista náo deixa de ser igualmente nacionalista e a obra insiste na rítmica nativa, mas entremeada de conteúdos jazzísticos e populares americanos - alguns de seus mitos sendo Ulysses em Copacabana surfando com James Joyce e Dorothy Lamour (1988), encomendada pelo Festival Internacional de Patras na Grécia, em 1989, com a presença do autor, ou Eisler $e$ Webern caminham pelos mares do Sul, estreada em Potsdam, na antiga RDA, em 1989, exemplos típicos.

Viajante inveterado, aberto ao passado e ao novo, penetra a fronteira da setuagenariedade na observação in loco de países que, visitados, profissionalmente substanciam-no através da sua compreensáo profunda das etnias ou das várias internacionali- 


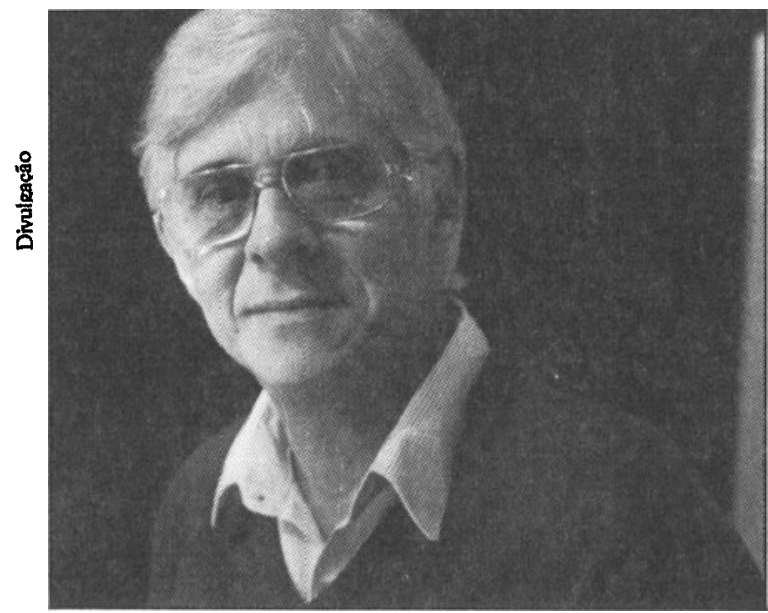

Gilberto Mendes

dades que autores como ele, de outras plagas, entendem-se em relacionamentos profícuos. México, Venezuela, Chile, Portugal, Espanha, Alemanha, Áustria, Grécia e os cursos universitários que ministrou como University Artist (1978-1979) em Wisconsin, Milwaukee e como Tinker Visiting Professor (1983) em Austin, Texas. Sob outro aspecto, em muitos dos países ocidentais a sua obra já foi apresentada.

A produção de Gilberto Mendes é extensa, dela fazendo parte: obra sinfônica, para piano e orquestra, camerística em formações singulares, coral, canto e piano e instrumental, onde se destaca a diversificada coleção pianística.

Gilberto Mendes, santista na acepção, fascinado pelo oceano e a praia, assim como pela sala de cinema ao escurecer - o seu templo preferido - , passo primeiro para o desvelamento do desfilar de seus ídolos Clark Gable, Greta Garbo, Gary Cooper e dos diretores Ingmar Bergman, Akira Kurosawa ou de muitos dos principais norte-americanos; é igualmente o denunciante da tragédia ou da hipocrisia do sistema em que vivemos.

Vila Socó (1983) e O uiltimo tango em Vila Parisi (1987) contêm cargas da crítica permanente ao descaso e, sob outra égide, Beba, Coca-Cola (1966) é a crítica ao consumismo, arquitetado pragmaticamente pelo sistema.

Professor do Departamento de Música da Escola de Comunicações e Artes da Universidade de São Paulo, Gilberto Mendes, neste ano de 1992, permanece rigorosamente pleno de insatisfaçôes: "aquele que cria, se estiver satisfeito, estanca", confessava-me ele; de um magistério em país que despreza a Cultura; do crítico sutil que perdeu espaços nos veículos que foram contaminados pela mídia comprometida; do pensador que compóe tentando compreender o absurdo do hoje.

* José Eduardo Martins é pianista e professor do Departamento de Música da ECA/USP. 